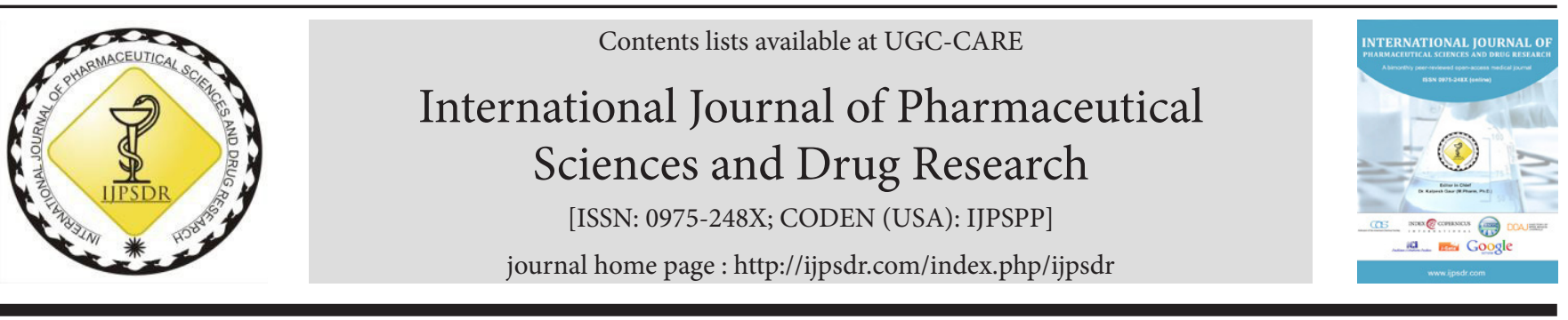

Research Article

\title{
Analytical QbD Approach for Development and Validation of RP-High Performance Liquid Chromatography Method for Determination of Tofisopam in Pure Form and Tablets
}

\author{
Megha Kokane ${ }^{1}$, Jeeja Pananchery ${ }^{1 *}$, Monika Jadhav ${ }^{2}$, Ashish Jain ${ }^{3}$ \\ ${ }^{1}$ Department of Quality Assurance, Shri. D. D. Vispute College of Pharmacy \& Research Center, New Panvel, Navi Mumbai-410206, Maharashtra, India. \\ ${ }^{2}$ Department of Quality Assurance, C. U. Shah College of Pharmacy, SNDT Women's University, Sir Vithaldas Thakersay, Santacruz West, Juhu, \\ Mumbai-400049, Maharashtra, India \\ ${ }^{3}$ Shri. D. D. Vispute College of Pharmacy \& Research Center, New Panvel, Navi Mumbai-410206, Maharashtra, India
}

\section{A R T I C L E I N F O \\ Article history: \\ Received: 13 January, 2020 \\ Revised: 20 February, 2020 \\ Accepted: 24 February, 2020 \\ Published: 30 March, 2020 \\ Keywords: \\ Analytical quality by design, \\ Method development, \\ QbD, Tofisopam, Validation, \\ Water, Acetonitrile. \\ DOI: \\ 10.25004/IJPSDR.2020.120210}

\begin{abstract}
A B S T R A C T
A novel, simple, optimized reversed-phase chromatography method for assay of Tofisopam in pure and tablet form is developed. The experimental trial was by Box Behnken design using the Design Expert ${ }^{\circledR}$ software 10 version. The attributes selected were peak symmetry, number of theoretical, and peak purity. The predicted data satisfied with actual experimental data. The optimized chromatographic conditions required a quaternary pump with a mobile phase of Water: Acetonitrile $25: 75 \mathrm{v} / \mathrm{v}$ at $1 \mathrm{~mL} / \mathrm{min}$, oven temperature at $25^{\circ} \mathrm{C}$ at $310 \mathrm{~nm}$ using $\mathrm{C}_{18}(250 \times 4.6 \mathrm{~mm} \mathrm{Id}, 5 \mu \mathrm{m})$ column and PDA detector with a run time of 5 min. The method was validated for linearity, precision, accuracy, and specificity. The method produced a linear response over a concentration range of 4-24 ppm with an overall average accuracy of $99.98 \%$. The method was robust, reproducible, and specific with respect to the retention time of tofisopam.
\end{abstract}

\section{INTRODUCTION}

Tofisopam is a antianxiety ${ }^{[1]}$ agent chemically known as 1-(3,4-Dimethoxyphenyl)-5-ethyl-7,8-dimethoxy-4methyl-5H-2,3-benzodiazepine Fig. 1. It is a white, pale yellowish-white crystalline powder, practically insoluble in water, sparingly soluble in ethanol, freely soluble in methanol, and acetonitrile with melting range $155-159^{\circ} \mathrm{C}^{[2]}$

There are analytical methods for the estimation of tofisopam with spectrophotometric and spectrofluorimetic $^{[3]}$ chromatographic, ${ }^{[4-6]}$ enantiomeric separation, ${ }^{[7,8]}$ gas-liquid chromatography (GLC), ${ }^{[9]}$ and super-critical chromatography ${ }^{[10]}$ method. All these methods require a large sample volume (1-5 $\mathrm{mL}$ ) and time-consuming sample clean up procedure. Literature reveals no RP-High<smiles>CCC1C(C)=NN=C(c2ccc(OC)c(OC)c2)c2cc(OC)c(OC)cc21</smiles>

Fig. 1: Structure of tofisopam

\footnotetext{
*Corresponding Author: Mrs. Jeeja Pananchery

Address: Department of Quality Assurance, Shri D. D. Vispute College of Pharmacy \& Research Center, New Panvel, Navi Mumbai-410206, Maharashtra, India Email $\bowtie$ : jeejapananchery@gmail.com

Relevant conflicts of interest/financial disclosures: The authors declare that the research was conducted in the absence of any commercial or financial relationships that could be construed as a potential conflict of interest.

Copyright (C) 2020 Megha Kokane et al. This is an open access article distributed under the terms of the Creative Commons Attribution- NonCommercialShareAlike 4.0 International License which allows others to remix, tweak, and build upon the work non-commercially, as long as the author is credited and the new creations are licensed under the identical terms.
} 
performance liquid chromatography method developed by quality by design for determination of tofisopam in pure form and tablet. In view of these points, an attempt was made to develop a simple, precise, accurate, and validated method for the determination of tofisopam in pure form and tablet by analytical quality by design approach.

\section{Materials AND Methods}

\section{Chemicals and Reagents}

The TF was gifted from Ajanta Pharmaceutical, Mumbai India. The commercial dose formulation containing $50 \mathrm{mg}$ TF, Nextril tablet, was procured from the local market. All the reagents and chemicals like acetonitrile, water, methanol were of HPLC grade.

\section{Instrumentation}

The determination of TF was done by using HPLC (JASCO LC system-1200 series), connected to the autosampler, column oven, and wavelength detector. It consists of a quaternary pump, a Rheodhyne injector with a $20 \mu \mathrm{L}$ loop, and a photodiode array detector. $\mathrm{C}_{18}(250 \times 4.6 \mathrm{~mm} \mathrm{Id}$, $5 \mu \mathrm{m})$ column was used for separation.

\section{Procedure for Standard Stock Solution}

The standard stock solution was prepared by accurately weighing $100 \mathrm{mg}$ of TF in $100 \mathrm{~mL}$ volumetric flask and diluted up to mark with acetonitrile, which gives a concentration of $1000 \mu \mathrm{g} / \mathrm{mL}$ of solution. From the above standard stock solution, an aliquot of $1 \mathrm{~mL}$ was transferred into $10 \mathrm{~mL}$ volumetric flask, and the volume was made up to the mark with acetonitrile, which gives a concentration of $100 \mu \mathrm{g} / \mathrm{mL}$ of solution (sub-stock solution).

\section{Preparation of Solution and Selection of Wavelength}

From the sub-stock solution $(100 \mu \mathrm{g} / \mathrm{mL})$, aliquot of $1 \mathrm{~mL}$ were transferred to $10 \mathrm{~mL}$ of volumetric flask and diluted with acetonitrile, to form a solution of $10 \mu \mathrm{g} / \mathrm{mL}$ and it was scanned in the range of $400-200 \mathrm{~nm}$, and the absorbance maximum was noted at $310 \mathrm{~nm}$ (Fig. 2).

\section{Optimization of Mobile Phase}

A variety of solvents with different compositions were screened to find out the ideal mobile phase (Table 1).

\section{Chromatographic Conditions}

The mobile phase was consists of acetonitrile: water (75:25), and it was filtered, degassed, and sonicated prior to use. $\mathrm{AC}_{18}(250 \times 4.6 \mathrm{~mm}$ Id, $5 \mu \mathrm{m})$ column was used as a stationary phase. The column temperature was kept at $25^{\circ} \mathrm{C}$ with a thermostatically controlled column oven. The flow rate was maintained at $1.0 \mathrm{~mL} / \mathrm{min}$. The detection was carried out at $310 \mathrm{~nm}$ wavelength PDA detector, and the injection volume was $20 \mu \mathrm{L}$.

\section{Experimental Design}

The experimental design was constructed using designexpert software version 10 for the study of different variables (oven temperature, percentage of the organic phase, and flow rate) and to verify method performances. The levels of these variables are as given in Table 2. The retention time, peak symmetry, peak purity, and several theoretical plates were used as a response in experimental design as controlling response, which is expected to affect and control method responses. A $3^{3}$ factorial design consisting of three factors at three levels was considered for the experimental plan. Initially and after confirming that the process is a non-linear, Box-Behnken design was used. The experimental observations along with Design (DOE) plan are shown in Table 3.

\section{Evaluation of Experimental Results and Selection of Final Method Conditions}

The different method conditions (13 runs) obtained from experimental design was run and evaluated for retention time, peak symmetry, number of theoretical plates, and peak purity. Response surface Box-Behnken statistical screening design was used to optimize and evaluate main effects, interaction effects, and quadratic effects. A 3-factor, 3-level design used is suitable for exploring quadratic response surfaces with Design Expert ${ }^{\circledR}$ (Version 10.0, Stat-Ease Inc).

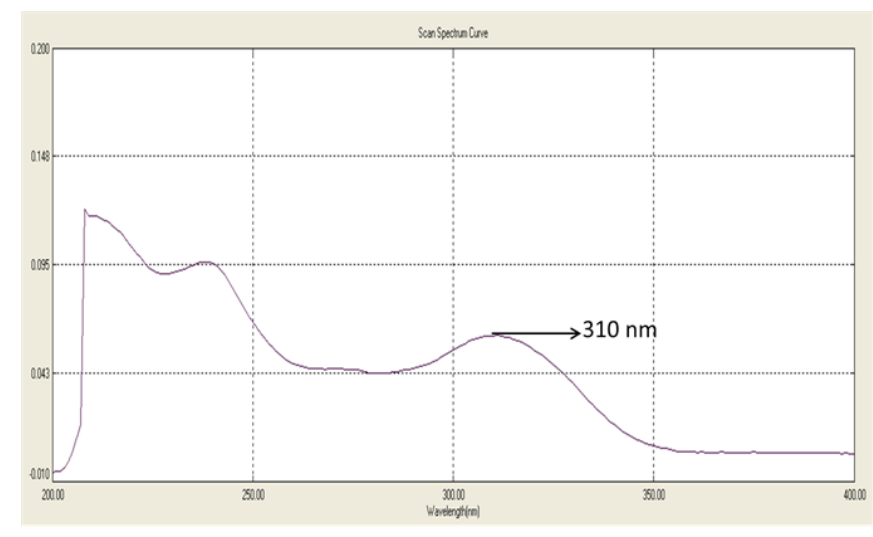

Fig. 2: UV spectrum of tofisopam

Table 1: List of mobile phase compositions screened

\begin{tabular}{llll}
\hline Sr. No. & Mobile phase & Ratio $(\mathrm{v} / \mathrm{v})$ & Remark \\
\hline 1 & Methanol : Water & $90: 10$ & Peak tailing was observed \\
2 & Methanol : Water & $80: 20$ & Peak fronting \\
3 & Methanol : Water & $70: 30$ & Peak was not proper \\
4 & ACN : Water & $90: 10$ & Peak was not resolved \\
5 & ACN : Water & $75: 25$ & Peak was symmetric \\
\hline
\end{tabular}


Analytical QbD Approach for Development and Validation of RP-HPLC Method for Determination of Tofisopam in Pure Form...

Table 2: Factors and levels of independent variables

\begin{tabular}{llll}
\hline Factors & Level 1 & Level 2 & Level 3 \\
\hline Percentage of the organic phase (in percentage) & 20 & 22.5 & 25 \\
Column temperature (degree Celsius) & 25 & 27.5 & 30 \\
Flow rate (mL/min) & 0.9 & 1 & 1.1 \\
\hline
\end{tabular}

Table 3: BoxBehnken Design Plan and Responses

\begin{tabular}{|c|c|c|c|c|c|c|c|c|}
\hline & & Factor 1 & Factor 2 & Factor 3 & Response 1 & Response 2 & Response 3 & Response 4 \\
\hline Std & Run & A: Oven temperature & B: Organic concentration & C: Flow rate & NTP & Peak symmetry & $R t$ & Peak purity \\
\hline 7 & 2 & 25 & 22.5 & 1.1 & 6271 & 0.996 & 3.923 & 99.19 \\
\hline 5 & 3 & 25 & 22.5 & 0.9 & 6275 & 1.027 & 4.753 & 99.55 \\
\hline 3 & 12 & 25 & 25 & 1 & 6445 & 0.998 & 4.46 & 98.89 \\
\hline 1 & 13 & 25 & 20 & 1 & 6027 & 1.045 & 4.14 & 98.37 \\
\hline 11 & 1 & 27.5 & 20 & 1.1 & 6928 & 1.081 & 3.737 & 99.11 \\
\hline 12 & 4 & 27.5 & 25 & 1.1 & 6724 & 1.092 & 3.95 & 98.08 \\
\hline 13 & 6 & 27.5 & 22.5 & 1 & 6632 & 1.036 & 4.227 & 99.22 \\
\hline 9 & 8 & 27.5 & 20 & 0.9 & 6456 & 1.106 & 4.543 & 99.14 \\
\hline 10 & 11 & 27.5 & 25 & 0.9 & 6315 & 1.09 & 4.917 & 99.15 \\
\hline 2 & 5 & 30 & 20 & 1 & 6512 & 1.103 & 4.08 & 99.49 \\
\hline 6 & 7 & 30 & 22.5 & 0.9 & 6676 & 1.108 & 4.687 & 99.11 \\
\hline 4 & 9 & 30 & 25 & 1 & 6216 & 1.064 & 4.443 & 98.09 \\
\hline 8 & 10 & 30 & 22.5 & 1.1 & 6128 & 1.094 & 3.867 & 98.97 \\
\hline
\end{tabular}

\section{Method Validation}

Method validation is an analytical process by which it is established by laboratory studies that the performance characteristics of the procedure meet the requirement for the intended analytical application.

\section{Linearity}

The linearity of TF was assessed in the range of (4-24 $\mu \mathrm{g} /$ $\mathrm{mL}$ ) in terms of slope, intercept, and correlation co-efficient values.

\section{Precision}

Precision study was calculated by interday and intraday studies. Both precisions were determined by analyzing 8 , $12,16 \mu \mathrm{g} / \mathrm{mL}$ concentrations daily for 3 days and \%RSD were calculated.

\section{Accuracy}

Accuracy of the method was confirmed by a recovery study from marketed formulation at 3-level of standard addition. Percentage recovery of TF was found out.

\section{Specificity}

Specificity was determined by checking the interference of any possible degradation products. Both the standard and test sample solutions were scanned separately in the range of $200-400 \mathrm{~nm}$.

\section{Ruggedness}

It was performed by analyzing three dilutions using different analysts on a different day. The overall \% RSD was calculated.

\section{Robustness}

The three dilutions were analyzed under different conditions by changing the wavelength and mobile phase composition. The percentage RSD of the assay was calculated.

\section{Stability in Analytical Solution}

Prepared sample as per test method and injected in duplicate into HPLC at initial and at different time intervals up to 24 hours. The percentage assay at different time intervals was determined.

\section{Assay}

For the assay of TF, twenty tablets were accurately weighed and triturated to make a fine powder. Quantity equivalent to $50 \mathrm{mg}$ was calculated and transferred into $50 \mathrm{~mL}$ volumetric flask, diluted with acetonitrile and sonicated for 15 minutes. From the above stock solution, $1 \mathrm{~mL}$ was transferred into $10 \mathrm{~mL}$ volumetric flask and diluted with acetonitrile, which gives a concentration of $100 \mu \mathrm{g} / \mathrm{mL}$ of solution. From the above solution, an aliquot of $1 \mathrm{~mL}$ was transferred into $10 \mathrm{~mL}$ of volumetric flask and diluted with acetonitrile, which givesa concentration of $10 \mu \mathrm{g} / \mathrm{mL}$ of solution. The $20 \mu \mathrm{L}$ of above dilution was injected for HPLC analysis.

\section{RESULTS AND DISCUSSION}

The proposed work was planned for the development and evaluation of the RP-HPLC method for the estimation of $\mathrm{TF}$ in bulk and pharmaceutical formulation. Accordingly, the initial solvent was selected for TF, and acetonitrile showed good solubility for it. Further, the chromatographic 
conditions were analyzed and parameters were finalized, as shown in Table 4. TF showed a sharp peak in mobile phase Acetonitrile: water (75:25) with retention time 4.46 minutes, as shown in Fig. 3.

\section{QbD Implementation}

Design Expert ${ }^{\circledR}$ (Version 10.0, Stat-Ease Inc) software was used for the statistical analysis of the experimental observations and the analysis was conducted by using Box-Behnken design. The inputs given to software are given in Tables $5 \mathrm{a}, \mathrm{b}$.

Inputs were given to the software and design was run, which provided selected 13 runs to be performed. After completing 13 runs, the results in terms of responses like retention time, peak symmetry, number of theoretical plates and peak purity were entered in software to give a statistical evaluation in terms of degrees of freedom (Tables 6 and 7) along with 3D surface plot of desirability as shown in Figs. 4-8.

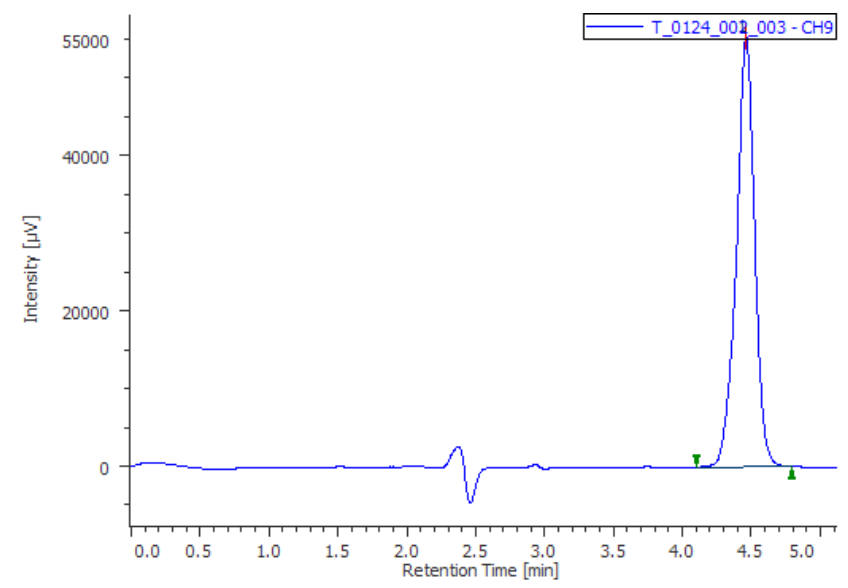

Fig. 3: Chromatogram of TF using ACN: Water (75:25)

Table 4: Chromatographic conditions

\begin{tabular}{ll}
\hline Parameters & Results \\
\hline Column & $\mathrm{C}_{18}(250 \times 4.6 \mathrm{~mm} \mathrm{Id}, 5 \mu \mathrm{m})$ column \\
Flow rate & $1.0 \mathrm{~mL} /$ minute. \\
Detector & $\mathrm{PDA}$ \\
Detector wavelength & $310 \mathrm{~nm}$ \\
Injection volume & $20 \mu \mathrm{L}$ \\
Retention time & $4.46 \mathrm{~min}$ \\
Mobile phase & Acetonitrile: water $(75: 25)$ \\
\hline
\end{tabular}

\section{Method Validation}

\section{Linearity}

The TF showed linearity between concentration range of 4-24 ppm and had a good correlation coefficient of 0.999 with slope 49297 and y-intercept 24739 for the graph of concentration against area Fig. 9.

\section{Precision}

Results of precision are shown in Table 8, and it shows a standard deviation of less than 2 , which indicates that the proposed method is precise.

\section{Accuracy}

Results of accuracy are shown in Table 9. The percentage recovery was 99.98 and also showed a standard deviation $<<2$, which states that the method is accurate.

\section{Specificity}

It was tested for the interference of any degraded substance, and as shown in the chromatogram (Fig. 10),
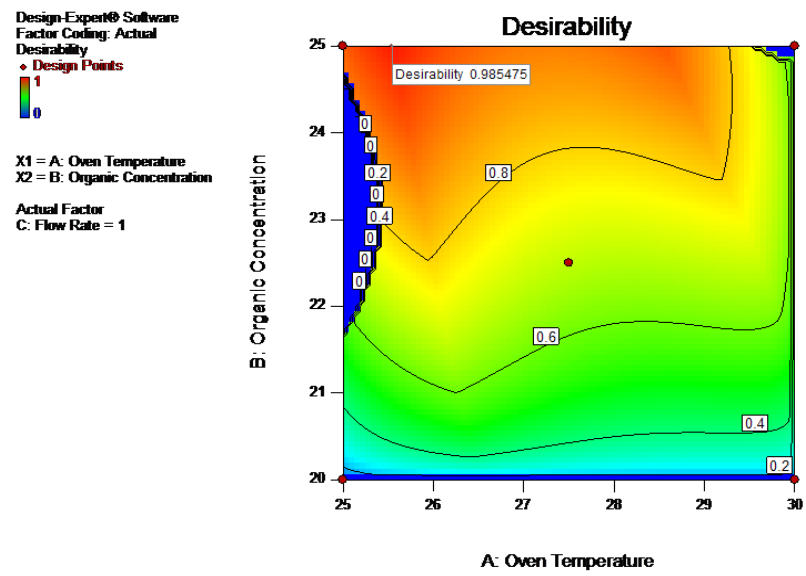

Fig. 4: Contour plot of desirability for obtaining optimized HPLC conditions

Table 5 (a): Design summary for optimization by using Box-Behnken design

\begin{tabular}{ll}
\hline Study type & Response surface \\
\hline Design type & Box-Behnken \\
Design model & Quadratic \\
Runs & 13 \\
\hline
\end{tabular}

Table 5 (b): Design summary for optimization by using Box-Behnken design

\begin{tabular}{|c|c|c|c|c|c|c|}
\hline Factor & Name & Units & Type & Subtype & Minimum & Maximum \\
\hline A & Oven temperature & Degree Celcius & Numeric & Continuous & 25 & 30 \\
\hline B & Organic concentration & $\%$ & Numeric & Continuous & 20 & 25 \\
\hline $\mathrm{C}$ & Flow rate & $\mathrm{mL} / \mathrm{min}$ & Numeric & Continuous & 0.9 & 1.1 \\
\hline
\end{tabular}

Table 6: Evaluation of degrees of freedom

\begin{tabular}{llllllll}
\hline Response & Name & Obs & Analysis & Minimum & Maximum & Ratio & Model \\
\hline R1 & NTP & 13 & Polynomial & 6027 & 6928 & 1.14949 & Quadratic \\
R2 & Peak Symmetry & 13 & Polynomial & 0.996 & 1.108 & 1.11245 & Quadratic \\
R3 & Rt & 13 & Polynomial & 3.737 & 4.917 & 1.31576 & Linear \\
R4 & Peak purity & 13 & Polynomial & 98.08 & 99.55 & 1.01499 & Quadratic \\
\hline
\end{tabular}




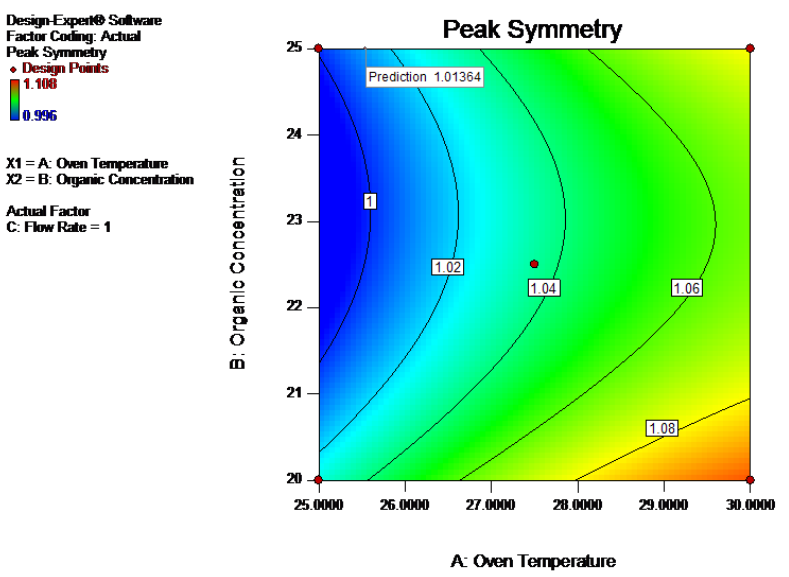

Fig. 5: Contour plot of peak symmetry

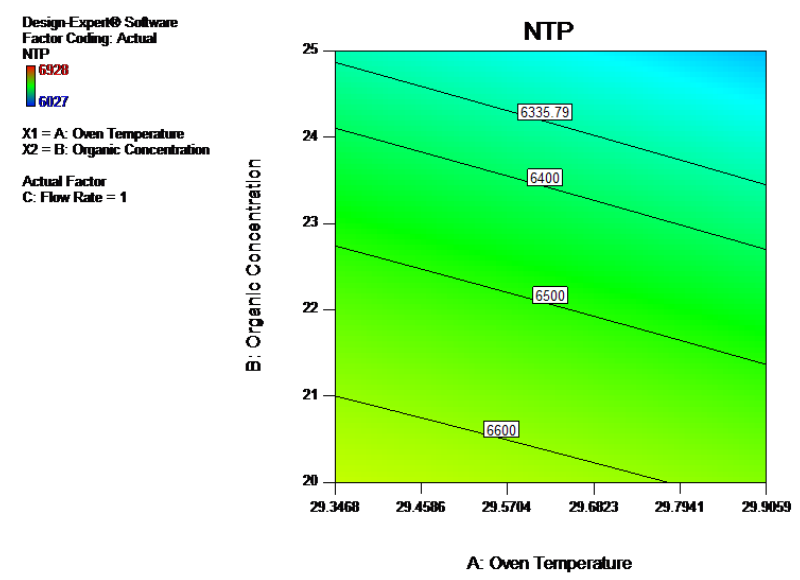

Fig. 7: Contour plot of NTP

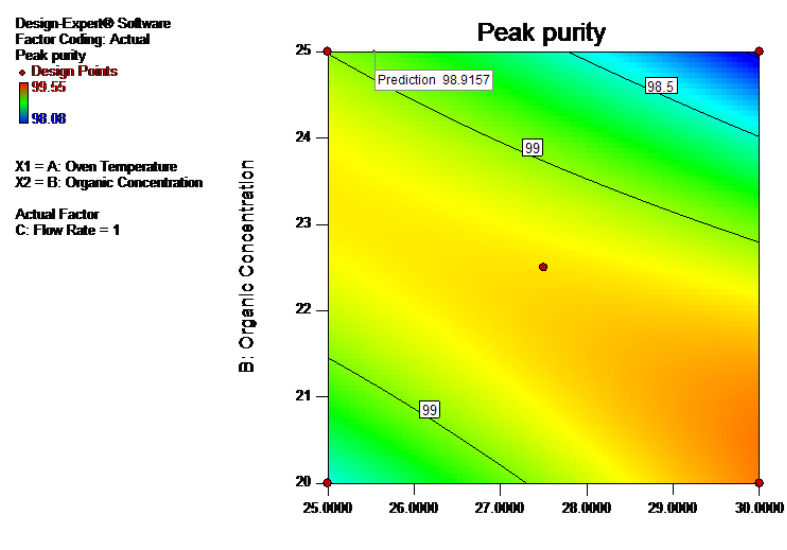

A. Oven Temperature

Fig. 6: Contour plot of peak purity
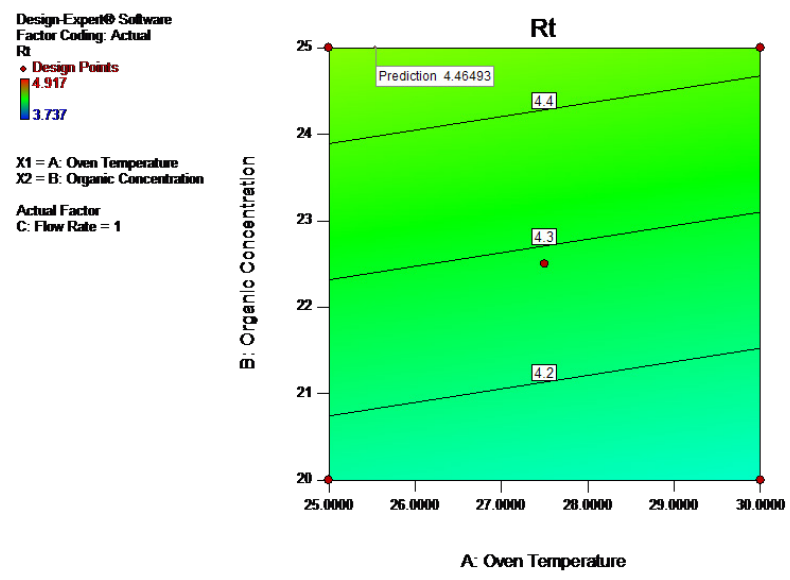

Fig. 8: Contour plot of Rt

Table 7: Obtained solutions for optimized condition

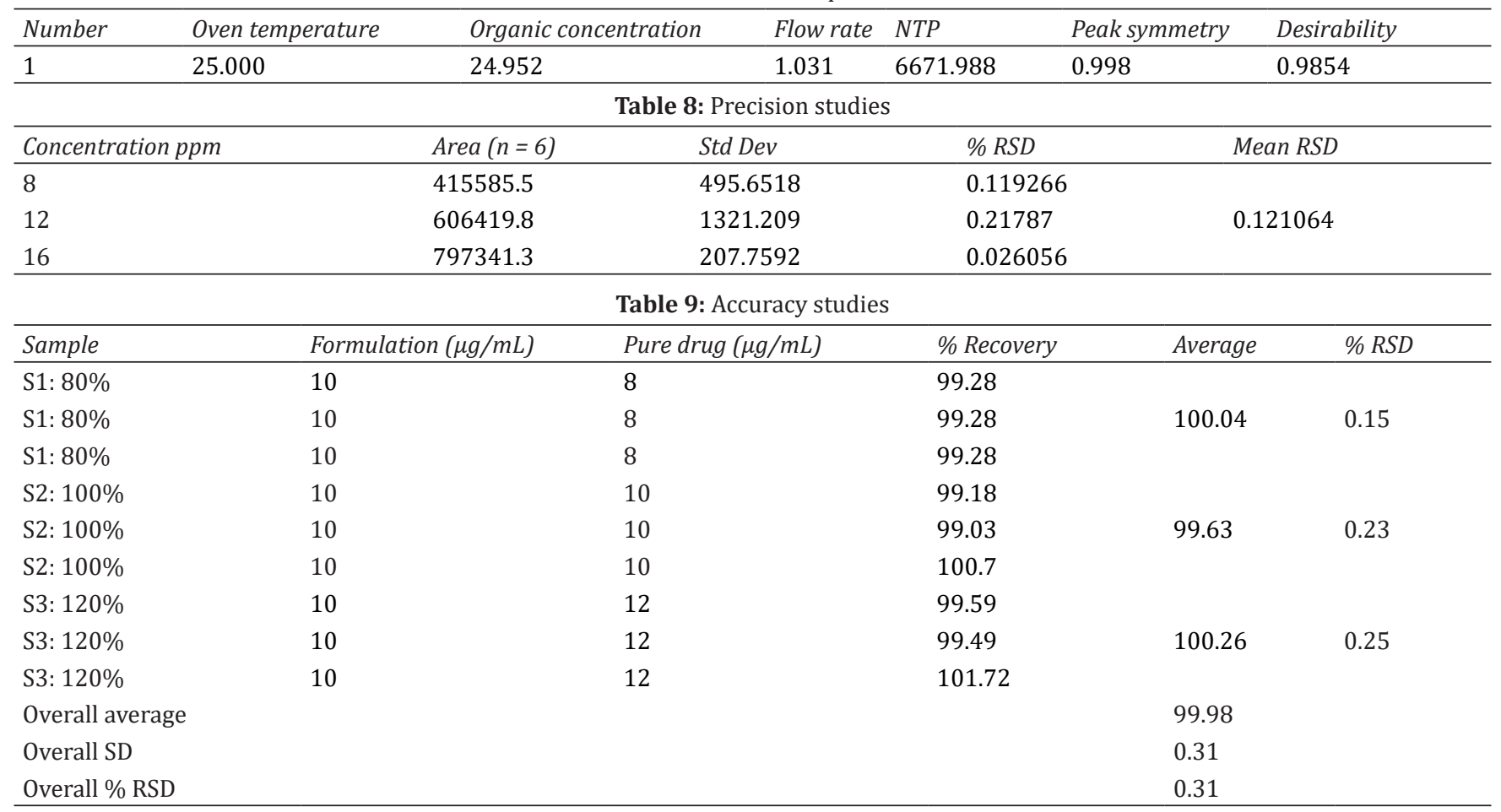




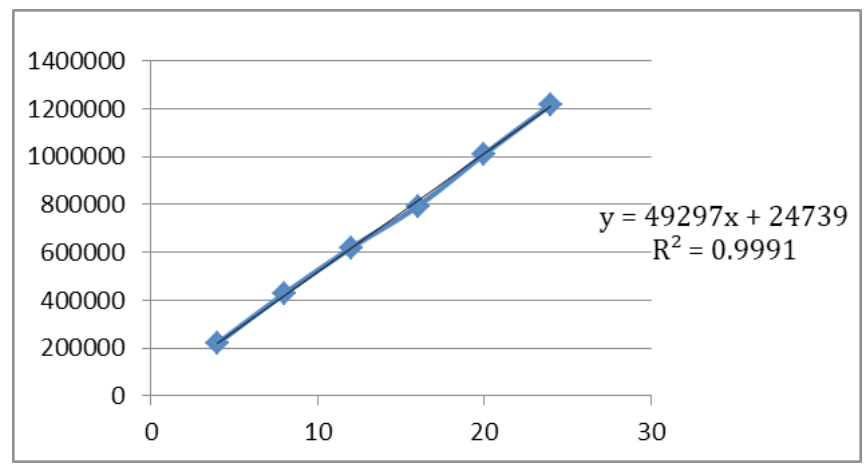

Fig. 9: Linearity curve of transfer factor at $310 \mathrm{~nm}$

there is no interference as it showed a clear peak without any another peak.

\section{Ruggedness}

It showed an average percentage 99.089 which is within range and standard deviation 0.185 which is less than 2 , indicating that the proposed method is satisfying criteria of ruggedness (Table 10).

\section{Robustness}

The results of robustness studies by varying mobile phase composition and wavelength are shown in (Table 11). RSD less than 2 indicated that the method is robust.

Solution Stability Studies

Table 12 shows the results for solution stability, and

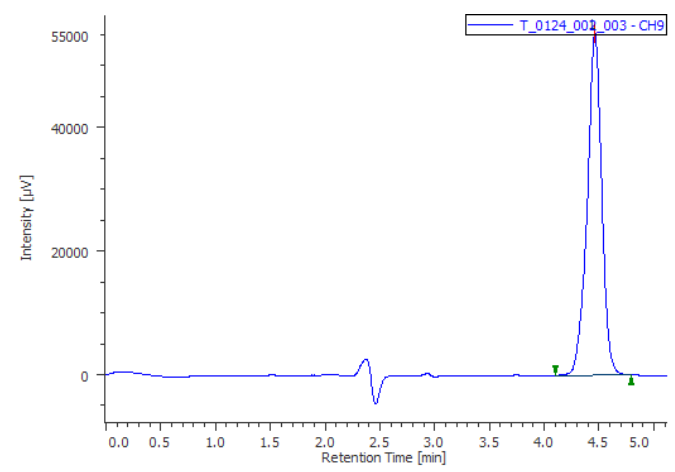

Fig. 10: Chromatogram of transfer factor for Specificity

Table 10: Ruggedness studies

\begin{tabular}{llc}
\hline Sr.No. & Analyst-1 & Analyst-2 \\
\hline Sample -1 & 99.40 & 99.09 \\
Sample -2 & 98.48 & 99.54 \\
Sample -3 & 98.71 & 100.68 \\
Sample -4 & 98.69 & 99.09 \\
Sample -5 & 98.61 & 99.31 \\
Sample -6 & 98.38 & 99.09 \\
Average & 98.71 & 99.46 \\
SD & 0.3593 & 0.621 \\
\%RSD & 0.363 & 0.624 \\
Overall average & & 99.089 \\
Overall SD & & 0.185 \\
Overall \%RSD & & 0.186 \\
\hline
\end{tabular}

Table 11: Robustness studies

\begin{tabular}{llllll}
\hline $\begin{array}{l}\text { Sample } \\
\text { ID }\end{array}$ & $\begin{array}{l}\text { Normal } \\
\text { condition }\end{array}$ & $\begin{array}{l}\text { Low } \lambda \text { max } \\
309 \mathrm{~nm}\end{array}$ & $\begin{array}{l}\text { High } \lambda \text { max } \\
311 \mathrm{~nm}\end{array}$ & $\begin{array}{l}\text { Low composition } \\
(74: 24)\end{array}$ & $\begin{array}{l}\text { High composition } \\
(76: 26)\end{array}$ \\
\hline Sample 1 & 99.40 & 98.6 & 98.8 & 100.3 & 99.4 \\
Sample 2 & 98.48 & 99.7 & 99.2 & 99.1 & 99.0 \\
Sample 3 & 98.71 & 98.5 & 100.9 & 99.7 & 99.5 \\
Sample 4 & 98.69 & - & - & - & - \\
Sample 5 & 98.61 & - & - & - & - \\
Sample 6 & 98.38 & - & - & - & 99.3 \\
Average & 98.71 & 98.9 & 99.6 & 99.7 & 0.26 \\
SD & 0.3593 & 0.67 & 1.12 & 0.60 & 0.27 \\
\% RSD & 0.363 & 0.67 & 1.12 & 0.60 & 99.0 \\
Overall Average & - & 98.9 & 99.1 & 99.1 & 0.28 \\
Overall SD & - & 0.35 & 0.69 & 0.52 & 0.28 \\
Overall & - & 0.36 & 0.69 & 0.53 & \\
\% RSD & & & & \\
\hline
\end{tabular}

Table 12: Solution Stability

\begin{tabular}{lll}
\hline Time Interval (hrs) & Area & $\%$ TF \\
\hline Initial & 514781 & 99.4 \\
8 & 510254 & 98.48 \\
16 & 511395 & 98.71 \\
24 & 511287 & 98.69 \\
Correlation (8) & & 0.98 \\
Correlation (16) & & 0.987 \\
Correlation (24) & & 0.986 \\
\hline
\end{tabular}


Analytical QbD Approach for Development and Validation of RP-HPLC Method for Determination of Tofisopam in Pure Form...

Table 13: Results of estimation of TF in tablet dosage form by HPLC method

\begin{tabular}{lllll}
\hline Tablet formulation & Label claim $(\mathrm{mg} / \mathrm{tab})$ & Label claim estimated $(\mathrm{mg} / \mathrm{tab})$ & Peak area & $\%$ RSD \\
\hline Tofisopam & 50 & $49.7 \pm 0.0577$ & $6672 \pm 13.04$ & 0.62 \\
\hline
\end{tabular}

Table 14: System suitability

\begin{tabular}{llll}
\hline Parameters & Tailing factor & Theoretical plate & $\%$ RSD \\
\hline Specificity & 0.934 & 5895.66 & 0.200 \\
Precision & 1.009 & 6674.66 & 0.121 \\
Linearity (range) & 0.997 & 6157.33 & 0.67 \\
Accuracy & 1.02 & 6665.33 & 0.313 \\
Solution stability 24 hours & 0.934 & 5928.667 & 0.397 \\
Ruggedness & 0.925 & 5895.667 & 0.30 \\
Robustness & 0.93 & 5928 & 0.363 \\
\hline
\end{tabular}

correlation was found to be less than $2,{ }^{[11]}$ indicating that TF is stable in acetonitrile: water (75:25).

Assay

Results of assay are shown in Table 13. The percentage of RSD was 0.62 which is within limits.

\section{Conclusion}

Tofisopam is an antianxiety drug. In this study, the concentration of organic phase, oven temperature, flow rate were considered as a qualitative variable that was controlled with three independent variables peak symmetry, retention time, and NTP. The experimental design suggested the robust MODR region for the TF HPLC method developed. All the validated parameters were within the acceptable criteria of ICH guidelines. Thus a simple, rapid, selective, precise, accurate, and robust HPLC method was developed for the estimation of TF in pure form and its tablet dosage form.

\section{ACKNOWLEDGMENT}

The authors express gratitude to Mumbai University for funding this project. We are thankful to the management of Shri. D.D.Vispute College of Pharmacy and Research Centre, New Panvel, Navi Mumbai, Maharashtra, India, for providing us the best facilities.

\section{REFERENCES}

1. Bond A, Lader MA. Comparison of the psychotropic profiles of tofisopam and diazepam.Eur J ClinPharmacol. 1982;22:137-142
2. Kokane M, Pananchery J, Jain. A Development and Validation of Spectrophotometric Method for the Determination of Tofisopam in Bulk and Pharmaceutical Formulation. Pharm Anal Acta. 2017;8:551.

3. Ramadan NK, Osman A. Fooad R, Moustafa A. Development and validation of spectrophotometric and spectrofluorimetric methods for simultaneous determination of tofisopam, JAPS. 2012;2:112119.

4. Choi SJ, Kim JS, Park EJ, Sohn DH, Lee HY, Baek SK, Lee HS. Analysis of tofisopam in human serum by column-switching semi-micro high-performance liquid chromatography and evaluation of to fisopambio equivalency, Biomed Chromatogr. 2002;16:277281.

5. Valentik M, Karaffa E, Ladányi L. Investigation of tofizopam impurities using high performance liquid chromatography, Acta Pharm Hung. 1993;63:57-65.

6. Xiaojuan G. Determination of main component in tofisopam tablet by HPLC, ZhongguoYaofang. 2010;21:3154-3155.

7. Hu P, Chen Y,Carr G, Guo J, Ye N. Method validation and determination of enantiomers and conformers in tofisopam drug substances and drug products by chiral high-performance liquid chromatography and kinetic and thermodynamic study of the interconversion of the conformers, J Chromatogr A. 2006;1129:47-53.

8. Cameron MD, Wright J, Black CB, Ye N. In vitro prediction and in vivo verification of enantioselective human tofisopam metabolite profiles., Drug Metab Dispos. 2007;35:1894-1902.

9. Gaillard Y, Gay-Montchamp JP, Ollagnie M. Simultaneous screening and quantitation of alpidem, zolpidem, buspirone and benzodiazepines by dualchannel gas chromatography using electron-capture and nitrogen-phosphorus detection after solidphase extraction. J. Chromatogr. 1993;622:197-208.

10. Salvador A, Herbreteau B, Dreux M, Karlsson A, Gyllenhaal O. Chiral supercritical fluid chromatography on porous graphitic carbon using commercial dimethyl $\beta$-cyclodextrins as mobile phase additive, J. Chromatography A. 2001;929:101-112.

11. ICH Harmonized Tripartite guidelines. Validation of Analytical Procedure: Text and Methodology, Q2 (R1), Geneva 2005:113.

HOW TO CITE THIS ARTICLE: Kokane M, Pananchery J, Jadhav M, Jain A. Analytical QbD approach for development and validation of RP-HPLC method for determination of tofisopam in pure form and tablets. Int. J. Pharm. Sci. Drug Res. 2020;12(2):159-165. D0I: 10.25004/IJPSDR.2020.120210 